\title{
Obesity: Is it an Independent Risk Factor for Diabetes and Cancer?
}

\author{
Jalal Hejazi ${ }^{1,2}$ and Reza Rastmanesh ${ }^{1,2 *}$
}

${ }^{1}$ Department of Clinical Nutrition \& Dietetics, Shahid Beheshti University of Medical Sciences, Tehran, Iran

${ }^{2}$ National Nutrition and Food Sciences Technology Research Institute, Tehran, Iran

\begin{abstract}
Today obesity is known as a causal or a strong risk factor for type 2 diabetes mellitus (T2D) and many of common cancers; however, is really obesity an independent risk factor for diabetes mellitus and cancer?

Studying the etiology of obesity, T2D and many types of cancers, we can see important common players. Genetic and epigenetic similarities between the diseases, role of microbiota in their development and progression, effect of life style related factors such as physical activity, diet and etc., are some of these players. Based on these evidences and also with recent identification of metabolically healthy obese individuals, the obese individuals whose mortality and morbidity rate is the same as non-obese people, we can conclude that obesity is not an independent risk factor for diabetes or cancer per se, and it is probably results from the same risk factors as these diseases. In this review we will explain the similarities between pathophysiology of obesity, cancer and diabetes and also coexisting conditions with obesity which may relate to cancer and T2D.
\end{abstract}

Keywords: Obesity; Cancer; Diabetes; Genetic; Epigenetic microbiota; Life style related factors; Signal pathways

Abbreviations: T2D: Type 2 Diabetes Mellitus; WHO: World Health Organization; BMI: Body Mass Index; IGF-1:Insulin-like Growth Factor; VEGF: Vascular Endothelial Growth Factor; PAI: Plasminogen Activator Inhibitor; FTO: Fat Mass and Obesity Associated; MC4R: Melanocortin-4 Receptor; TNF- $\alpha$ : Tumor Necrosisfactor-alpha; TRAIL: Tumor Necrosis Factor (TNF)-Related Apoptosis-inducing Ligand; mTOR: The Mammalian Target of Rapamycin; IRS: Insulin Receptor Substrates; SAT: Subcutaneous Adipose Tissue; VAT: Visceral Adipose Tissue

\section{Introduction}

According to the World Health Organization(WHO) estimation, at present, there are about one billion overweight people worldwide and at least 300 million people are obese [1]. Because of its general application and feasibility, body mass index (BMI) is the method most commonly used as a surrogate measure for obesity [2]. Based on the diagnostic criteria of the WHO, obesity is defined as BMI $30 \mathrm{~kg} / \mathrm{m}^{2}$ and more and overweight is defined as BMI $25-30 \mathrm{~kg} / \mathrm{m}^{2}$ [2].

In numerous studies, obesity has been considered as the one of the main causes of diabetes mellitus and many types of cancers or at least a strong association has been reported between obesity and an increased risk of diabetes mellitus and many kinds of common cancers $[1,3,4]$. The most acceptable mechanism which explains the links between obesity and diabetes is that obesity is a state of low grade systemic inflammation which can cause insulin resistance in muscle, liver, and adipose tissue [5]. Also Excessive nutrient intake promotes adipocyte hypertrophy, another hallmark of obesity, resulting in mitochondrial dysfunction and increased oxidative stress, as well as endoplasmic reticulum stress, and thus adipose tissue dysfunction [6]. These disturbances in the physiological function of adipose tissue play an important role in the development and progression of type 2 diabetes mellitus. Regarding cancer, it has been estimated that, overall, overweight and obesity cause about $20 \%$ of all cancer cases [7]. The reported possible mechanisms for this association includes: increased circulating levels of insulin, bioavailable insulin-like growth factor (IGF)-1, leptin, inflammatory factors, and vascular integrityrelated factors such as vascular endothelial growth factor(VEGF) and plasminogen activator inhibitor (PAI)-1 [3].
Although the development of obesity is largely driven by the consumption of high-energy food and a sedentary lifestyle, it is also influenced by many other factors [8]. When studying the etiology of obesity, we can see the role of genetic, epigenetic modifications, gut microbiota and life style related factors. All of these factors have also important role in the pathophysiology of diabetes and cancer. As a result it seems obesity is not an independent causal or risk factor for diabetes and cancer, but rather results from some of the same risk factors that influence diabetes and cancer. Also when reviewing the literature, recently we can see some phrases such as "Metabolically Healthy Obese individuals" [9] or "Metabolically Obese but NormalWeight" [10]. These phrases clearly show that obesity per se is not necessarily a risk factor for diabetes or cancer because metabolically healthy individuals have high insulin sensitivity, favorable cholesterol levels, and normal blood pressure, despite excess adiposity [11]. On the other hand it is plausible from the idea of metabolically obese normal weight individuals that, the distribution of adiposity in the body is more important in determining risk of metabolic disorders and cancer than obesity. In the following paragraphs we will explain the similarities between etiology of obesity, diabetes mellitus and cancer and it will be clarified that some co-existing conditions with obesity also may play role in the development or progression of diabetes or cancer.

\section{Genetic and Epigenetic}

Along with environment, genetic has an undeniable role in the development of obesity. Twin studies estimate heritability of BMI to be $40-70 \%$ in children and adults [12]. Like many other diseases, obesity genome-wide studies of association have implicated multiple loci in the

*Corresponding author: Dr. Reza Rastmanesh, Faculty of Nutrition, Arghavane Gharbi, Farahzadi Blvd, Shahrake Gharb, PO Box 19395-4741, Tehran, Iran, Tel: 9821-22357484; Fax: 9821-22360660; E-mail: rezar@sbmu.ac.ir

Received September 13, 2013; Accepted October 08, 2013; Published October 14,2013

Citation: Hejazi J, Rastmanesh R (2013) Obesity: Is it an Independent Risk Factor for Diabetes and Cancer? J Mol Genet Med S1: 001. doi:10.4172/1747-0862.S1 002

Copyright: ( 2013 Hejazi J, et al. This is an open-access article distributed under the terms of the Creative Commons Attribution License, which permits unrestricted use, distribution, and reproduction in any medium, provided the original author and source are credited 
recent years. However the most robust common obesity susceptibility locus found to date is the fat mass and obesity associated (FTO) gene following bymelanocortin-4 receptor (MC4R) [13]. The association between polymorphism of these loci and different cancers has been reported by several studied [14-16]. Some studies have shown that this association is independent from BMI [14,17]. There are also clear evidences from association of genetic variation in FTO and MC4R with type 2 diabetes [18]. There is also evidence that shows this association remains significant after adjusting for BMI [19].

In the past few years, epigenetics emerged as a complementary model to explain the rapid emergence of obesity and metabolic disorders [20]. Although there is ample evidence that epigenetic is likely to play a role in the pathogenesis of obesity, T2D and cancer, epigenetic studies of obesity and type 2 diabetes are still in an early stage in humans [21]. However there are many studies about the role of epigenetic alterations in cancer [22]. The hypomethylation of DNA in tumors as compared with the level of DNA methylation in their normal-tissue counterparts was one of the first epigenetic alterations to be found in human cancer [23]. During the development of a neoplasm, the degree of hypomethylation of genomic DNA increases as the lesion progresses from a benign proliferation of cells to an invasive cancer [24]. Another cancer related epigenetic alteration is hypermethylation of the $\mathrm{CpG}$ islands in the promoter regions of tumor-suppressor genes which is a major event in the origin of many cancers [22]. In terms of diabetes and obesity it has been shown that inter-individual DNA methylation variations is associated with different individual susceptibility to Type 2 Diabetes Mellitus and obesity [25]. Associations of the FTO risk allele with hypermethylation have now been demonstrated and replicated in several studies, [25-27] but it remains unclear whether methylation is the causal link between the FTO risk allele and T2D or obesity [25].

Although there is still a long way to understand the epigenetic links between obesity, T2D and cancer completely, there is little doubt that nutritional and other exposures during early life generate long-term changes that later predispose the individual to obesity, T2D and cancer [21].

\section{Microbiota}

The gut microbiota in the human body consists of wide range of bacteria, many of which are playing important roles in human health, including metabolism, homeostasis of the immune system, and in colonization resistance. However, imbalances in gut microbiota is related to numerous disorders, such as cancers, diabetes and obesity [28] The reason for this dysbiosis (alterations in the microbial community) is not clear yet but dietary habits probably can play a role in this area [29]. Recently the possible role of gut microbiota in the development of obesity and metabolic disorders has gained many attentions [30]. The evidences from animal models suggest that it is possible that the microbiota of obese subjects has higher capacity to harvest energy from the diet providing substrates that can activate lipogenic pathways. In addition, microorganisms can also influence the activity of lipoprotein lipase, interfering in the accumulation of triglycerides in the adipose tissue [31]. Also gut microbiota-derived lipopolysaccharide is a key molecule involved in the early development of inflammation and metabolic diseases [32]. As we know inflammation is one of the mechanisms which are proposed to explain why obesity increases cancer risk and now we can see that, at least to some extent, the inflammation is attributable to the microbiota and not obesity per se. A recent study has proposed that microbiota promotes epithelial cell proliferation through local activation of the IL- 6 pathway and thus leading tofaster cancer growth [33]. The relationship between microbiota with several cancers especially gastrointestinal related cancers has been reported by various studies [34-36].

\section{Life Style Related Factors}

Life style related factors which are associated with etiology of obesity, T2D and cancer are very vast, including dietary habits, physical activity, alcohol consumption, smoking and etc. Here we just review effects of some of the most important of these factors in the patho physiology of the diseases.

\section{Calorie intake}

Obesity develops when energy intake exceeds energy expenditure for a prolonged time. Thus intake of calorie dense foods was considered as the main reason of obesity during the last decades. At the other end of the spectrum, several studies on animals and human have shown that dietary energy restriction inhibits mammary cancers [37-38]. Several mechanisms have been proposed in this area including elevated levels of sirtuin 1(SIRT1) [39]. or suppression of insulin-like growth factor-I (IGF-I) receptor [40]. In terms of T2D it has been shown that energy restriction even without weight reduction can enhance insulin sensitivity [41]. As a result it is probable that excess calorie intake and not necessarily obesity itself is a risk factor for diabetes and cancer growth.

\section{Other dietary factors}

It is expected that obese people to have unhealthier dietary habits such as western dietary pattern compared with normal weight individuals [42]. The association between these dietary habits such as high intake of saturated fatty acids or low intake of fruits and vegetables on insulin resistance and many types of cancer is well established [4346]. In the other words there are probably lots of dietary factors which can be considered as risk factors for both obesity and T2D and cancer.

\section{Physical activity}

Regular physical activity is associated with enhanced sense of health and well-being. The results of numerous studies have revealed that regular physical activity can reduce the risk of obesity, T2D and many types of cancers [47]. The associated mechanisms include, decrease in endogenous sexual hormones (estradiol, estrone, testosterone) levels and increase in generation of sex hormone-binding globulin [48], decrease in production of pro-inflammatory cytokines such as tumor necrosis factor-alpha (TNF- $\alpha$ ) and interleukin 6 (IL-6) [49], increases in the levels of antioxidant enzymes and reduction of oxidative stress [50].

In contrast sedentary and inactive life style which are some of the main causes of obesity also is an important risk factor for T2D and cancer $[51,52]$.

\section{Signal Pathways in the Development of Obesity, Diabetes and Cancer}

Several signal pathways have been proposed in the pathogeneses of cancer, T2D and obesity. We can see lots of similarities between these signal pathways in these diseases. Here we will explain some of the most important of them.

\section{TRAIL}

TNF-related apoptosis-inducing ligand (TRAIL) is a protein 
originally identified for its ability to modulate cancer cell death. More over it has been shown that TRAIL regulates homeostasis of the immune system, infection, and autoimmune diseases, all known to involve inflammation [53]. Recently, TRAIL has been implicated in the pathogenesis of diabetes, obesity, and metabolic diseases, highlighting a possible mechanistic link between cancer, obesity, diabetes, and inflammation [54]. Although there are lots of controversies about the role of TRAIL in obesity, T2D and cancer, there is substantial evidence that TRAIL is protective against obesity, diabetes and cancer in murine models and in vitro systems [54].

\section{mTOR}

The mammalian target of rapamycin (mTOR), is a serine/ threonine kinase that regulates cell growth and metabolism in response to diverse external stimuli [55]. During the past few decades, the mTOR-mediated pathway has been shown to promote tumorigenesis through the coordinated phosphorylation of proteins that directly regulate cell-cycle progression and metabolism, as well as transcription factors that regulate the expression of genes involved in the oncogenic processes [56]. Besides tumorigenesis, deregulation of mTORC1 is also involved in many other human diseases and metabolic disorders, including T2D and obesity [57]. Both T2D and obesity are associated with insulin resistance. It has been demonstrated that one of the causes is dysfunction of the insulin receptor substrates (IRS) via a negative feedback loop from mTOR-S6K [58].

\section{Fat Distribution}

In 1947, for the first time Jean Vague proposed that the android obesity phenotype is a common feature in metabolic abnormalities associated with type 2 diabetes and cardiovascular disease [31]. Today it is widely accepted that abdominal adiposity is an important risk factor for metabolic disease and cancer than is general adiposity [59]. Abdominal obesity has both subcutaneous adipose tissue (SAT) and visceral adipose tissue (VAT). Because VAT secretes adipo cytokines and other vaso active substances that can influence the risk of developing metabolic traits, it is considered as a pathogenic fat depot [60]. Thus it is plausible that some forms of fat distribution and not obesity in general can be considered as risk factors for diabetes and cancer. In agreement with this hypothesis, an analysis in National Health and Nutrition Examination Survey III data showed that higher BMI in both sexes were associated with increased survival in older adults, while a higher waist-to-hip ratio or waist-to-thigh ratio either decreased or did not influence risk of death [61].

\section{Conclusion}

Taking all together obesity is not an independent causal or risk factor for diabetes and cancer but it rather results as a consequence from some of the same risk factors enhancing diabetes and cancer. There are similarities between pathogenesis of obesity, T2D and many type of cancer. Similarities in genetic and epigenetic predisposition, role of micro biota, life style related risk factors, signal pathways and etc. These findings are in agreement with a previous hypothesis by the authors [62]. According to this hypothesis, there are common links between various chronic diseases, and disturbance of regulatory mechanisms in different levels (gene expression, transcription, post transcription) is probably the root of the degenerative diseases.

\section{References}

1. Westley RL, May FE (2013) A twenty-first century cancer epidemic caused by obesity: the involvement of insulin, diabetes, and insulin-like growth factors. Int J Endocrinol 2013: 632461
2. Seidell JC, Kahn HS, Williamson DF, Lissner L, Valdez R (2001) Report from a Centers for Disease Control and Prevention Workshop on use of adult anthropometry for public health and primary health care. Am J Clin Nutr 73 : 123-126.

3. Ford NA, Lashinger LM, Allott EH, Hursting SD (2013) Mechanistic targets and phytochemical strategies for breaking the obesity-cancer link. Front Oncol 3: 209.

4. Gallagher EJ, LeRoith D (2013) Epidemiology and molecular mechanisms tying obesity, diabetes, and the metabolic syndrome with cancer. Diabetes Care 36 Suppl 2: S233-239

5. Samuel VT, Shulman GI (2012) Mechanisms for insulin resistance: common threads and missing links. Cell 148: 852-871.

6. Odegaard JI, Chawla A (2013) Pleiotropic actions of insulin resistance and inflammation in metabolic homeostasis. Science 339: 172-177.

7. Wolin KY, Carson K, Colditz GA (2010) Obesity and cancer. Oncologist 15 556-565.

8. Morris MJ (2008) Cardiovascular and metabolic effects of obesity. Clin Exp Pharmacol Physiol 35: 416-419.

9. Durward CM, Hartman TJ, Nickols-Richardson SM (2012) All-cause mortality risk of metabolically healthy obese individuals in NHANES III. J Obes 2012 460321.

10. Lopez-Miranda J, Perez-Martinez P (2013) It is time to define metabolically obese but normal-weight (MONW) individuals. Clin Endocrinol (Oxf) 79: 314315

11. Blüher M (2010) The distinction of metabolically 'healthy' from 'unhealthy' obese individuals. Curr Opin Lipidol 21: 38-43.

12. Herrera BM, Keildson S, Lindgren CM (2011) Genetics and epigenetics of obesity. Maturitas 69: 41-49.

13. Xia Q, Grant SF (2013) The genetics of human obesity. Ann N Y Acad Sci 1281: 178-190

14. Delahanty RJ, Beeghly-Fadiel A, Xiang YB, Long J, Cai Q, et al. (2011) Association of obesity-related genetic variants with endometrial cancer risk: a report from the Shanghai Endometrial Cancer Genetics Study. Am J Epidemio 174: $1115-1126$

15. Lin Y, Ueda J, Yagyu K, Ishii H, Ueno M, et al. (2013) Association between variations in the fat mass and obesity-associated gene and pancreatic cancer risk: a case-control study in Japan. BMC Cancer 13: 337

16. Kaklamani V, Yi N, Sadim M, Siziopikou K, Zhang K, et al. (2011) The role of the fat mass and obesity associated gene (FTO) in breast cancer risk. BMC Med Genet 12: 52

17. lles MM, Law MH, Stacey SN, Han J, Fang S, et al. (2013) A variant in FTO shows association with melanoma risk not due to BMI. Nat Genet 45: 428-432, $432 \mathrm{e} 1$.

18. Vasan SK, Karpe F, Gu HF, Brismar K, Fall CH, et al. (2013) FTO genetic variants and risk of obesity and type 2 diabetes: A meta-analysis of 28,394 Indians. Obesity (Silver Spring)

19. Takeuchi F, Yamamoto K, Katsuya T, Nabika T, Sugiyama T, et al. (2011) Association of genetic variants for susceptibility to obesity with type 2 diabetes in Japanese individuals. Diabetologia 54: 1350-1359.

20. Stöger R (2008) Epigenetics and obesity. Pharmacogenomics 9: 1851-1860.

21. Drong AW, Lindgren CM, McCarthy MI (2012) The genetic and epigenetic basis of type 2 diabetes and obesity. Clin Pharmacol Ther 92: 707-715.

22. Esteller M (2008) Epigenetics in cancer. N Engl J Med 358: 1148-1159.

23. Feinberg AP, Vogelstein B (1983) Hypomethylation distinguishes genes of some human cancers from their normal counterparts. Nature 301: 89-92.

24. Fraga MF, Herranz M, Espada J, Ballestar E, Paz MF, et al. (2004) A mouse skin multistage carcinogenesis model reflects the aberrant DNA methylation patterns of human tumors. Cancer Res 64: 5527-5534.

25. Toperoff G, Aran D, Kark JD, Rosenberg M, Dubnikov T, et al. (2012) Genomewide survey reveals predisposing diabetes type 2-related DNA methylation variations in human peripheral blood. Hum Mol Genet 21: 371-383.

26. Bell CG, Finer S, Lindgren CM, Wilson GA, Rakyan VK, et al. (2010) Integrated 
Citation: Hejazi J, Rastmanesh R (2013) Obesity: Is it an Independent Risk Factor for Diabetes and Cancer? J Mol Genet Med S1: 001. doi:10.4172/17470862.S1-002

genetic and epigenetic analysis identifies haplotype-specific methylation in the FTO type 2 diabetes and obesity susceptibility locus. PLoS One 5: e14040.

27. Almén MS, Jacobsson JA, Moschonis G, Benedict C, Chrousos GP, et al. (2012) Genome wide analysis reveals association of a FTO gene variant with epigenetic changes. Genomics 99: 132-137.

28. Kim BS, Jeon YS, Chun J (2013) Current Status and Future Promise of the Human Microbiome. Pediatr Gastroenterol Hepatol Nutr 16: 71-79.

29. Turner ND, Ritchie LE, Bresalier RS, Chapkin RS (2013) The microbiome and colorectal neoplasia: environmental modifiers of dysbiosis. Curr Gastroentero Rep 15: 346

30. Sanz Y, Rastmanesh R, Agostonic C (2013) Understanding the role of gut microbes and probiotics in obesity: how far are we? Pharmacol Res 69: 144-

31. Boroni Moreira AP, Fiche Salles Teixeira T, do C Gouveia Peluzio M, de Cássia Gonçalves Alfenas R (2012) Gut microbiota and the development of obesity. Nutr Hosp 27: 1408-1414.

32. Everard A, Cani PD (2013) Diabetes, obesity and gut microbiota. Best Pract Res Clin Gastroenterol 27: 73-83.

33. Hu B, Elinav E, Huber S, Strowig T, Hao L, et al. (2013) Microbiota-induced activation of epithelial IL- 6 signaling links inflammasome-driven inflammation with transmissible cancer. Proc Natl Acad Sci U S A 110: 9862-9867.

34. Farrell JJ, Zhang L, Zhou H, Chia D, Elashoff D, et al. (2012) Variations of oral microbiota are associated with pancreatic diseases including pancreatic cancer. Gut 61: 582-588.

35. Compare D, Nardone G (2011) Contribution of gut microbiota to colonic and extracolonic cancer development. Dig Dis 29: 554-561.

36. Jobin C (2013) Colorectal cancer: looking for answers in the microbiota. Cancer Discov 3: 384-387.

37. Omar HA, Berman-Booty L, Weng JR (2012) Energy restriction: stepping stones towards cancer therapy. Future Oncol 8: 1503-1506.

38. Zhang FF, John EM, Knight JA, Kaur M, Daly M, et al. (2013) Total energy intake and breast cancer risk in sisters: the Breast Cancer Family Registry. Breast Cancer Res Treat 137: 541-551.

39. Zhu Z, Jiang W, McGinley JN, Thompson HJ (2013) Defining the role of histone deacetylases in the inhibition of mammary carcinogenesis by dietary energy restriction (DER): effects of suberoylanilide hydroxamic acid (SAHA) and DER in a rat model. Cancer Prev Res (Phila) 6: 290-298

40. Chu PC, Kulp SK, Chen CS (2013) Insulin-like growth factor-I receptor is suppressed through transcriptional repression and mRNA destabilization by a novel energy restriction-mimetic agent. Carcinogenesis .

41. Dean DJ, Brozinick JT Jr, Cushman SW, Cartee GD (1998) Calorie restriction increases cell surface GLUT-4 in insulin-stimulated skeletal muscle. Am J Physiol 275: E957-964

42. Esmaillzadeh A, Azadbakht L (2008) Major dietary patterns in relation to genera obesity and central adiposity among Iranian women. J Nutr 138: 358-363.

43. Chan JM, Gong Z, Holly EA, Bracci PM (2013) Dietary Patterns and Risk of Pancreatic Cancer in a Large Population-Based Case-Control Study in the San Francisco Bay Area. Nutr Cancer 65: 157-164.

44. Yusof AS, Isa ZM, Shah SA (2012) Dietary patterns and risk of colorecta cancer: a systematic review of cohort studies (2000-2011). Asian Pac J Cancer Prev 13: 4713-4717.

45. Campbell PT, Sloan M, Kreiger N (2008) Dietary patterns and risk of incident gastric adenocarcinoma. Am J Epidemiol 167: 295-304.
46. Malik VS, Fung TT, van Dam RM, Rimm EB, Rosner B, et al. (2012) Dietary patterns during adolescence and risk of type 2 diabetes in middle-aged women. Diabetes Care 35: 12-18.

47. Kruk J (2007) Physical activity in the prevention of the most frequent chronic diseases: an analysis of the recent evidence. Asian Pac J Cancer Prev 8: 325 338

48. McTiernan A, Wu L, Chen C, Chlebowski R, Mossavar-Rahmani Y, et al. (2006) Relation of BMI and physical activity to sex hormones in postmenopausa women. Obesity (Silver Spring) 14: 1662-1677.

49. Panagiotakos DB, Pitsavos C, Chrysohoou C, Kavouras S, Stefanadis C ATTICA Study (2005) The associations between leisure-time physical activity and inflammatory and coagulation markers related to cardiovascular disease: the ATTICA Study. Prev Med 40: 432-437.

50. Kruk J, Aboul-Enein HY (2007) Physical activity and cancer prevention: updating the evidence. The role of oxidative stress in carcinogenesis. Cur Cancer Ther Rev 3: 81-95.

51. Wang D, Zheng W, Wang SM, Wang JB, Wei WQ, et al. (2012) Estimation of cancer incidence and mortality attributable to overweight, obesity, and physical inactivity in China. Nutr Cancer 64: 48-56.

52. Admiraal WM, van Valkengoed IG, L de Munter JS, Stronks K, Hoekstra JB et al. (2011) The association of physical inactivity with Type 2 diabetes among different ethnic groups. Diabet Med 28: 668-672.

53. Wiley SR, Schooley K, Smolak PJ, Din WS, Huang CP, et al. (1995) Identification and characterization of a new member of the TNF family that induces apoptosis. Immunity 3: 673-682.

54. Harith HH, Morris MJ, Kavurma MM (2013) On the TRAIL of obesity and diabetes. Trends Endocrinol Metab.

55. Laplante M, Sabatini DM (2012) mTOR signaling in growth control and disease. Cell 149: 274-293.

56. Dobashi Y, Watanabe Y, Miwa C, Suzuki S, Koyama S (2011) Mammalian target of rapamycin: a central node of complex signaling cascades. Int $\mathrm{J}$ Clin Exp Pathol 4: 476-495

57. Inoki K, Corradetti MN, Guan KL (2005) Dysregulation of the TSC-mTOR pathway in human disease. Nat Genet 37: 19-24.

58. Zhou H, Huang S (2010) The complexes of mammalian target of rapamycin. Curr Protein Pept Sci 11: 409-424.

59. Janssen I, Katzmarzyk PT, Ross R (2004) Waist circumference and not body mass index explains obesity-related health risk. Am J Clin Nutr 79: 379-384.

60. Fox CS, Massaro JM, Hoffmann U, Pou KM, Maurovich-Horvat P, et al. (2007) Abdominal visceral and subcutaneous adipose tissue compartments association with metabolic risk factors in the Framingham heart study. Circulation 116: 39-48

61. Reis JP, Macera CA, Araneta MR, Lindsay SP, Marshall SJ, et al. (2009) Comparison of overall obesity and body fat distribution in predicting risk of mortality. Obesity (Silver Spring) 17: 1232-1239.

62. Hejazi J, Rastmanesh R, McCarty MF (2012) Common pathologic pathways: a single prescription dream? Med Hypotheses 79: 553-554. 